\title{
Review: The Consumption of Ultra-Processed Foods and Non-communicable Diseases in Latin America
}

\author{
Rodrigo A. Matos ${ }^{1 *}$, Michelle Adams ${ }^{2 *}$ and Joan Sabaté ${ }^{2}$ \\ ${ }^{1}$ EP Ingeniería de Industrias Alimentarias, Facultad de Ingeniería y Arquitectura, Universidad Peruana Unión, Lima, Peru, \\ ${ }^{2}$ Center for Nutrition, Healthy Lifestyle, and Disease Prevention, School of Public Health, Loma Linda University, Loma Linda, \\ CA, United States
}

OPEN ACCESS

Edited by:

Giuseppe Grosso,

NNEdPro Global Centre for Nutrition and Health, United Kingdom

Reviewed by:

José María Huerta Instituto de Salud Carlos III

(ISCIII), Spain

Tiziano Verri,

University of Salento, Italy

${ }^{*}$ Correspondence:

Rodrigo A. Matos

amatosch@upeu.edu.pe

Michelle Adams

mdadams@/lu.edu

Specialty section:

This article was submitted to

Nutritional Epidemiology,

a section of the journal

Frontiers in Nutrition

Received: 29 October 2020 Accepted: 24 February 2021

Published: 24 March 2021

Citation:

Matos RA, Adams M and Sabaté J (2021) Review: The Consumption of

Ultra-Processed Foods and

Non-communicable Diseases in Latin America. Front. Nutr. 8:622714.

doi: 10.3389/fnut.2021.622714
The objective of this article is to assess current trends in Latin America with respect to the consumption of ultra-processed foods and non-communicable diseases. This review addresses the rapid growth of the ultra-processed foods market in Latin America which, along with other social and environmental factors, has been shown to be highly influential in the prevalence of non-communicable diseases such as obesity, type 2 diabetes, hypertension and cardiovascular disease, cancer, and all-cause mortality. Ultra-processed foods represent a health concern for a number of reasons. They are generally calorically dense and high in sodium, sugar, and saturated and trans fats, and low in fiber and protein. Additionally, they may contain additives and neoformed compounds that affect health in ways that have not been adequately researched. Furthermore, the packaging of ultra-processed foods may contain hormone disruptors whose effects on humans are not entirely clear. Associations between ultra-processed foods and cardio-metabolic dysfunction, as well as several plausible mechanisms, will be evaluated.

Keywords: ultra-processed foods, chronic disease, metabolic disease, cardiovascular disease, diabetes, Latin America

\section{INTRODUCTION}

Ultra-processed foods (UPF) are food products that have been manufactured through the use of multiple industrial techniques (1). These techniques can include hydrogenation, extrusion, pre-frying and/or the addition of colorants, emulsifiers, and preservatives. Employing ultra-processing techniques allows manufacturers to create products that are hyper-palatable, cheap to produce, easy to market, and able to sit on store shelves or remain in the kitchen cabinet for years without spoiling.

While these foods are not new, their consumption is becoming increasingly widespread in Latin America. At the same time, the prevalence of excess adiposity and the cardio-metabolic sequelae commonly associated with it have also risen (2-4). Latin Americans are becoming increasingly westernized in their food preferences, and the health consequences of this cultural shift are overwhelmingly harmful.

Evidence from cross-sectional and prospective studies points to a strong association between UPF consumption and overweight/obesity (5-7), hypertension (8), cardiovascular disease (CVD) (9), type-2 diabetes (10), cancer (11), and all-cause mortality risk (12-14). UPF deliver a poor 
TABLE 1 | NOVA food classification system according to its level of processing.

\begin{tabular}{ll}
\hline Food classification & Food example \\
\hline Unmodified or minimally & Fresh/frozen fruits and vegetables, fresh meat, \\
processed foods & fresh milk, grains, eggs, fresh fish, nuts, \\
& hranola, rice, beans, tubers, whole grain flour, \\
processed foods as processed spices, etc. & $\begin{array}{l}\text { Extracted vegetable oils, substances isolated } \\
\text { culinary ingredients }\end{array}$ \\
or modified by various preservation methods, \\
salt, sugar, oil, fat, flour, white rice, pasta, \\
butter extracted from fresh milk, extracted \\
honey, starches extracted from corn and other \\
plants, etc. \\
Vegetables and legumes modified or preserved \\
with additives, salty or sugary nuts and seeds, \\
canned meats and fish, canned fruits, fresh \\
whole grain breads, fresh cheese, etc. \\
Industrial formulas with multiple ingredients, \\
including: soft drinks, energy drinks, fruit nectar \\
drinks, alcoholic beverages, distilled \\
beverages, beer, refined cereal, breads, \\
ready-to-eat meals, instant cereals, cookies, \\
candy, sugary drinks, margarine, mayonnaise, \\
chips, instant soups, confectionery, jams, \\
chocolate, ice cream, cake, energy bars, dairy \\
drinks, yogurts, processed cheese, pizza, \\
pasta dishes, instant sauces, processed meat \\
products, meat analogs, infant formulas, \\
weight loss products such as meal \\
replacement shakes and powders, etc. \\
Ultra-processed foods
\end{tabular}

Source: Adapted from Monteiro et al. (1).

nutrient profile (15) and their additives disrupt gut function (1618). The packaging, while attractive, may be adding additional health risks $(19,20)$. To date, only one randomized controlled trial assessing the impact of UPF on cardio-metabolic health has been published, and the findings suggest that UPF consumption can lead to passive overeating and subsequent weight gain (21).

The objective of this article is to assess current trends in Latin America with respect to UPF consumption and cardio-metabolic diseases, highlighting the importance of this unfavorable connection as well as possible mechanisms.

\section{AN OVERVIEW OF ULTRA-PROCESSED FOODS}

Multiple classification systems have been developed for the purpose of distinguishing the level of processing a food has received. For research purposes, the most commonly utilized system (22) is the NOVA food classification system (23). This system places foods into one of four categories: unprocessed/minimally processed, processed culinary ingredients, processed foods, and ultra-processed foods (Table 1).

Foods which carry the distinction of being ultra-processed share a few defining characteristics. From the point of view of the consumer, they are convenient, hyper-palatable, and cheap. From the manufacturer's point of view, these foods are economical to produce, easy to advertise, and have a long-shelf life, all of which favor profit. Nutritionally, high concentrations of sodium, sugar, hydrogenated oils, and additives are common to UPF. They tend to be energy dense and contain more saturated fat, trans fat, and free sugar along with lower levels of fiber, protein, sodium, and potassium when compared to minimally processed foods (24).

Critics of the NOVA system claim that its simplicity is inadequate to contribute to dietary guidelines, and that a dietary pattern which contains UPF may not necessarily be micronutrient-poor and hyper-palatable (25).

\section{CONCERNS SURROUNDING THE INTAKE OF ULTRA-PROCESSED FOODS}

Putting whole foods through any type of processing fundamentally alters their food matrix, typically in a detrimental manner. For one, UPF are generally dense in calories from sugar and saturated fat but poor in fiber and micronutrients, a combination which contributes unfavorably to a healthy diet pattern (15). They are also more likely to contain trans fats, which have been definitively classified as harmful for cardiovascular health (26).

The additives found in these foods also have questionable effects on health. Carrageenan and carboxymethylcellulose (CMC), thickening agents commonly employed in meat and dairy product formulations, have been shown to be associated with intestinal inflammation (18). It has been posited that the underlying mechanisms are likely to involve damage to the endothelial barrier, upregulation of pro-inflammatory cytokines, and interference with the immune response. Noncaloric artificial sweeteners, often used in the place of sugar in products that are advertised as being low in sugar or sugarfree, may also contribute to metabolic dysfunction by causing gut dysbiosis (16). Emulsifiers, a ubiquitous class of stabilizers commonly added to processed foods, have been shown to induce metabolic syndrome and colonic inflammation in mice (17).

The packaging of ultra-processed and processed foods adds an additional layer of concern. Synthetic compounds like bisphenol A (BPA) are omnipresent in food packaging, and BPA in particular has been shown to act as a xenohormone with the potential to impair reproductive function in men and increase cancer risk (19). While some manufacturers have responded to the public's concerns about BPA exposure by switching to bisphenol S (BPS), research indicates that this alternative may actually be more readily absorbed into the body (27). Phthalates are another class of synthetic chemicals commonly used in food packaging, and like BPA and BPS, they have the potential to act as xenohormones. Among individuals in the National Health and Nutrition Examination Survey (NHANES) 2013-2014 cohort, intake of UPF was correlated with increased exposure to phthalates (20).

Nevertheless, it is important to recognize that food processing has provided many benefits to society. Nutritious foods such as whole grain bread, canned beans, and frozen spinach are all examples of processed foods. Processes such as pasteurization decrease the risk of microbial contamination. Applying heat 
to food prior to consumption makes many foods easier to digest, and it has been theorized that cooking with fire contributed significantly to human evolution and advancement (28). Phytonutrients such as lycopene are significantly more bioavailable after heat-processing (29). The enrichment and fortification of processed foods provides micronutrients which certain vulnerable populations may have trouble consuming sufficient amounts of $(30,31)$. Additionally, many processed foods are designed to cater to specific sub-populations with chewing and swallowing difficulties, such as people living with dysphagia (32). Processing food is not inherently bad, but the displacement of minimally processed foods in favor of these foods warrants concern.

\section{CONCURRENT TRENDS IN THE INTAKE OF ULTRA-PROCESSED FOODS AND CHRONIC DISEASES IN LATIN AMERICA}

The consumption of UPF is growing exponentially in Latin America countries (2). In a joint effort, the World Health Organization (WHO) and the Pan American Health Organization (PAHO) conducted an epidemiological study in 13 countries throughout Latin America with the goal of determining how the increasing prevalence of UPF in Latin American markets was affecting the chronic disease burden of these countries (2). The following countries were included in this study: Argentina, Bolivia, Brazil, Chile, Colombia, Costa Rica, Dominican Republic, Ecuador, Mexico, Peru, Uruguay, Venezuela, and Guatemala. Between 2000 and 2013, the retail sales of ultra-processed products, which encompasses both foods and beverages, from fast-food outlets increased in almost all 13 countries, with Argentina and Venezuela being the exception due to financial crises (Figure 1).

Overall, there is a positive association between annual retail sales of UPF and the prevalence of obesity in Latin America (2). Figures 2, 3 depict this correlation. In Brazil, the increasing intake of processed foods, sugar-sweetened beverages (SSBs), and refined carbohydrates has occurred in tandem with the rising prevalence of overweight and obesity in that country (3). These concurrent trends have been identified as major causes of death from cardio-metabolic diseases in Brazil. Between 2002 and 2009, intake of UPF in Brazilian households increased from $20.8 \%$ of total calories to $25.4 \%$ (33). As intake of UPF increased, intake of minimally processed foods also decreased.

As retail sales for fast foods have risen in Latin America, so has the prevalence of diabetes (34).

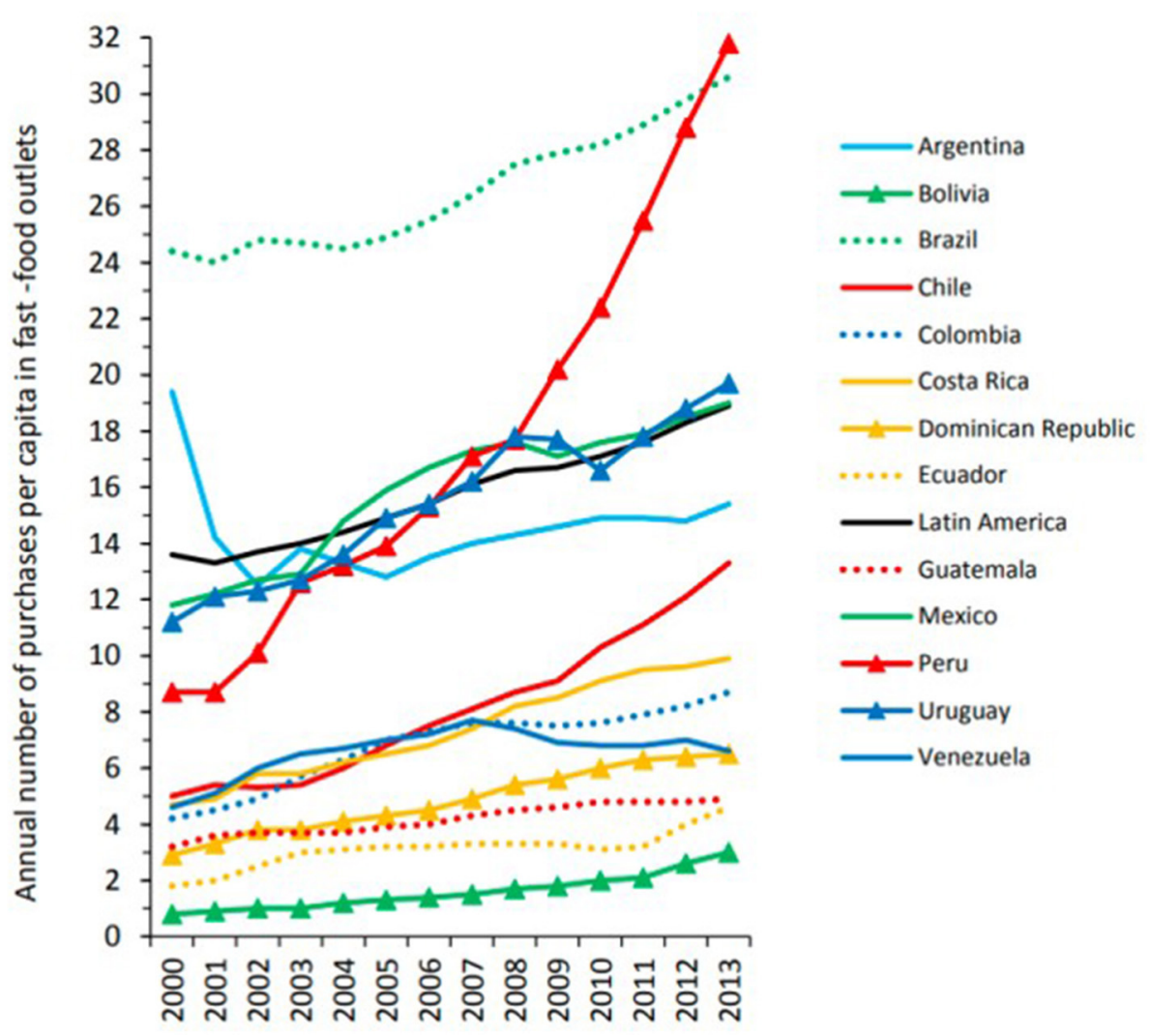

FIGURE 1 | Annual number of purchases per capita in fast-food outlets in 13 Latin American countries, 2000-2013. Purchases refers to single, completed purchases (which may include more than one meal). Fast-food outlets are defined as establishments offering limited menus prepared quickly where customers order, pay, and pick up from a counter. Data are from the Euromonitor Passport Database (2014). Source (2). 


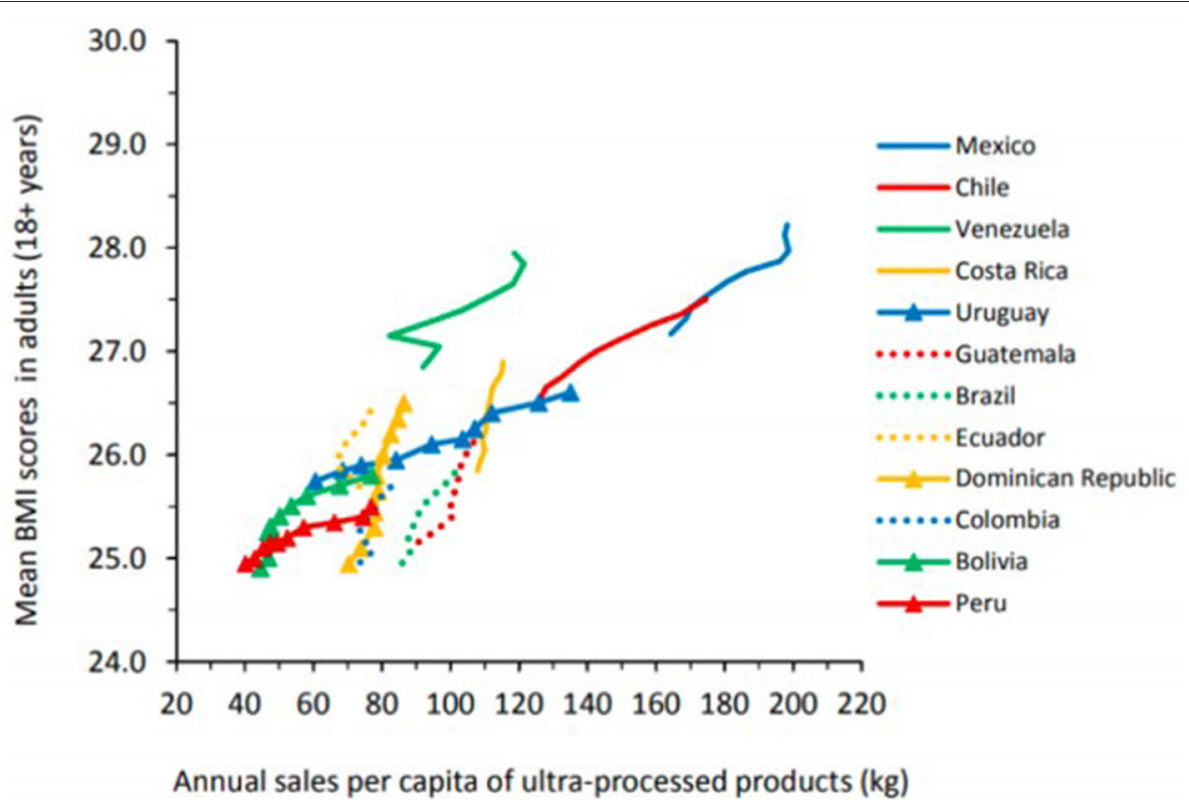

FIGURE 2 | Annual sales per capita of ultra-processed food and drink products and mean body mass index (BMI) scores in 12 Latin American coutries, $2000-2009$. Ultra-processed products here include carbonated soft drinks, sweet and savory snacks, breakfast cereals, confectionary (candy), ice cream, biscuits (cookies), fruit and vegetable juices, sports and energy drinks, ready-to-drink tea or coffee, spreads, sauces, and ready-meals. Source (2).

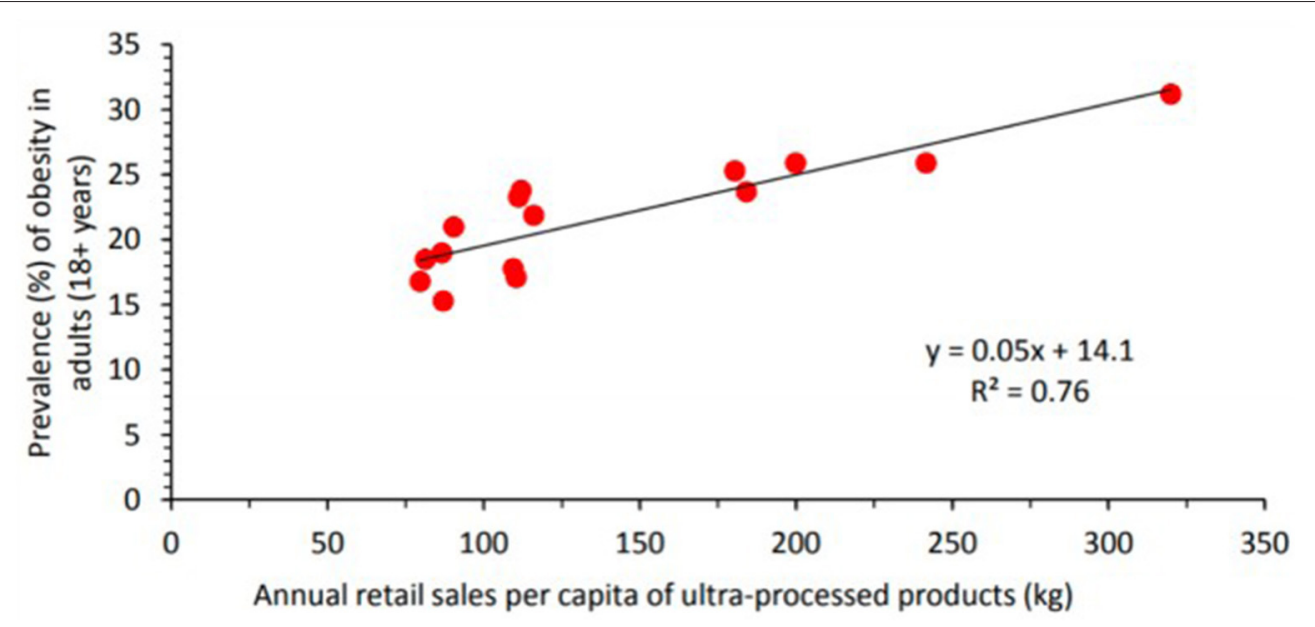

FIGURE 3 | Annual retail sales per capita of ultra-processed food and drink products and prevalence of obesity (\%) in adults in 14 countries (Bolivia, Brazil, Chile, Colombia, Costa Rica, Dominican Republic, Ecuador, Guatemala, Mexico, Peru, Uruguay, Venezuela, Canada, and the United States) in the Americas, 2013. Ultra-processed products here include carbonated soft drinks, sweet and savory snacks, breakfast cereals, confectionary (candy), ice cream, biscuits (cookies), fruit and vegetable juices, sports and energy drinks, ready-to-drink tea or coffee, spreads, sauces, and ready-meals. Source (2).

Within the span of the last decade, the prevalence of diabetes rose from 10.8 to $13.5 \%$ in Mexico, 6.4 to $10.4 \%$ in Brazil, and 5.7 to $8.6 \%$ in Chile (Figure 4). Argentina and Venezuela also experienced moderate $(<1 \%)$ increases in diabetes prevalence. The only country to experience a notable decline in diabetes prevalence was the Dominican Republic, where there was a $2.6 \%$ reduction in diabetes prevalence. This ecological correlation between UPF sales per capita and diabetes prevalence invites discussion about a potential causal relationship between these two factors.

An assessment of diet quality conducted among children in the Bogotá School Children Cohort provides evidence that the nutrient profiles of UPF consumed in this region tend to be incongruent with good health (35). Specifically, these foods are lower in omega-3 polyunsaturated fatty acids, calcium, zinc, and vitamins $\mathrm{A}, \mathrm{C}, \mathrm{E}$, and $\mathrm{B} 12$ when compared to unprocessed or minimally processed foods consumed in the same population. 


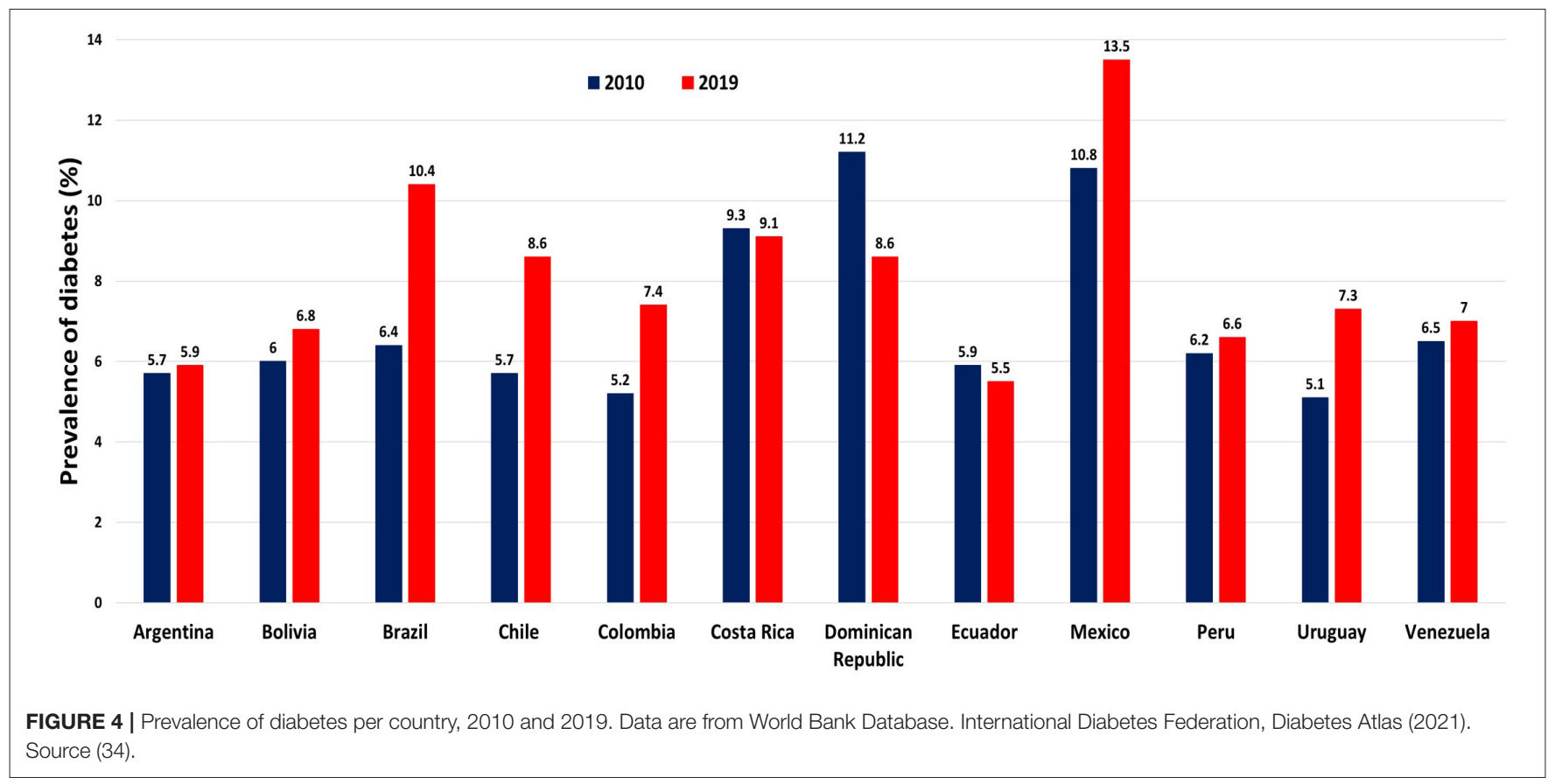

In Chile, UPF have been shown to contribute 58.6\% (standard error $0.9 \%$ ) of all added sugars consumed in the diet in a national sample (36). Soft drinks, fruit juices and flavored beverages, and cookies, cakes, and pies were the most commonly consumed high-sugar UPF among Chileans. Excessive consumption of added sugars has been correlated with increased cardiovascular disease risk (37).

This is concerning, particularly in the context of the latest data on food intake in Latin America which was collected as part of the Latin American Study of Nutrition and Health (ELANS) study (38). In this cross-sectional study, 24-h recall data from 9,218 adolescents and adults living in Argentina, Brazil, Chile, Colombia, Costa Rica, Ecuador, Peru, and Venezuela was assessed for intake of foods associated with non-communicable disease (NCD) risk. It was determined that $<3.5 \%$ of respondents were meeting the WHO recommendations for intake of vegetables, whole grains, nuts, yogurt, and fish. A mere 7.2\% of participants reported that they were consuming sufficient quantities of fruits and vegetables. If the trend in UPF intake continues, the number of Latin Americans who are eating a diet that is protective against NCDs will decline, and the prevalence of NCDs will continue to escalate.

While Venezuelans do not appear to be spending much on ultra-processed foods in the retail sector, it is worth noting that the typical Venezuelan diet still contains significant amounts of ultra-processed foods. Goodman and colleagues (39) collected data from a nationally representative sample of Venezuelans between 2014 and 2017 and found that traditional foods such as arepas and yucca remain staples in the Venezuelan diet and have not been replaced by more Western foods. In this country, Western fare like French fries and burgers are consumed once a month or less by three quarters of the population. Nevertheless, with a median consumption of one per day (interquartile range: IQR: $0.43-3$ portions per day), the traditional foods that were most consumed in Venezuela-arepas and cheesecould still be classified as ultra-processed foods according to the NOVA classification system. Interestingly, there was a negative correlation between the prevalence of hypertension and type 2 diabetes and intake of arepas. This may be attributable to post-diagnostic changes in behavior.

\section{SOCIAL DETERMINANTS IN THE SALES INCREASE OF ULTRA-PROCESSED FOODS IN LATIN AMERICA}

The following factors all contribute to the observed increase in the sale of ultra-processed foods in Latin-American countries: urbanization, foreign investment, and market deregulation. While the volume of sales of ultra-processed foods is higher in high-income countries like the United States, the rate of sales growth is higher in lower-income countries. It is evident that middle- and low-income countries are becoming increasingly attractive markets for the producers of ultra-processed drinks and foods.

The growing presence of UPF in grocery stores in Latin America places consumers in an environment that is challenging to navigate for several reasons (40). Firstly, relative to fresh foods, UPF tend to be sold at lower prices, an important factor for the millions of Latin Americans who are living in precarious financial situations. Secondly, the processed food labels often contain misleading health claims which may sway consumers to purchase a particular product with the aim of improving their health when in reality that product may be affecting their 
health negatively. And finally, food advertisers often aim their marketing tactics at children who are particularly susceptible to the effects of media (41). While television advertisements for ultra-processed foods and beverages abound on Latin American television, advertisements of minimally or unprocessed foods are difficult to come by (42).

Of note, the trends in intake of UPF vary country to country. As previously mentioned, economic crises have stymied the growth of the UPF market in Argentina and Venezuela (2). Meanwhile, daily per capita sales of SSBs is approximately 200 milliliters ( $\mathrm{ml}$ ) per capita per day in Colombia, while in Mexico that number is closer to $450 \mathrm{ml}$ per capita per day (4). Per capita daily junk food sales is also twice as high in Mexico as it is for all of Latin America, while Chile is experiencing the fastest increase in sales of both SSB and junk food (4). While the overall sales volume varies widely between countries, the trend of reducing intake of traditional foods in favor of ultra-processed foods transcends nations.

\section{THE LINK BETWEEN THE INTAKE OF ULTRA-PROCESSED FOODS AND CHRONIC DISEASES}

The displacement of whole foods in the diet by UPF is becoming increasingly associated with all forms of disease risk.

\section{Overweight/Obesity}

The association between the intake of UPF and the risk of being overweight or obese was assessed in numerous studies (Table 2), one of which is the NutriNet-Santé cohort study (5). After following 110,260 adults (mean age $43.1 \pm 14.6$ years, $78.2 \%$ female) living in France for 10 years (2009-2019), researchers were able to conclude that intake of UPF is positively associated with risk of overweight (hazard ration (HR) for 10\% absolute increase: 1.11, 95\% confidence interval (CI): 1.08-1.14) and obesity (HR for 10\% absolute increase: 1.09, 95\% CI:1.05-1.13) after adjusting for energy intake, age, sex, education, physical activity, tobacco and alcohol use, marital status, and number of 24-h diet records. These findings are consistent with the findings of the Seguimiento Universidad de Navarra (SUN) Project, a Spanish prospective study wherein consumption of ultra-processed foods was also found to be associated with an increased risk of overweight and obesity (6). In another Spanish cohort, the Seniors Study on Nutrition and Cardiovascular Risk in Spain: Seniors-ENRICA-1 cohort (mean age 67.1 \pm 5.8 years, $44 \%$ female), it was found that consuming UPF increased participants' likelihood of having abdominal obesity, a risk factor for cardio-metabolic dysfunction (7).

Similar results were obtained from a longitudinal study conducted in Latin America by Canhada and colleagues (43). This cohort consisted of 11,827 participants living in Brazil (mean age $51.3 \pm 8.7$ years $55.0 \%$ female). Mean follow up time was 3.8 years, and diet was assessed via food frequency questionnaire. After adjusting for a variety and social and lifestyle factors, a significant positive association between intake of UPF and being at an unhealthy weight [relative risk (RR): 1.27, 95\%
CI: 1.07-1.50] as well as risk of gaining weight (RR:1.33, 95\% CI: $1.12-1.58)$ was detected in this cohort.

In a cross-sectional Brazilian study $(n=30,243)$, researchers found that adolescents and adults with the highest intake of UPF according to the Brazilian Dietary Survey had significantly greater odds of being obese [odds ratio (OR): 1.98, 95\% CI: 1.263.12] (46). The validity of this association is further supported by a cross-sectional study of NHANES data collected from 15,977 American adults, wherein UPF intake was found to be associated with greater adiposity, especially for females (45). The same association has been reported in a Canadian study as well (44).

There has been only one randomized controlled trial assessing the effects of UPF on health to date (21). Twenty adults (mean age $31.2 \pm 1.6$ years, $50 \%$ female) were randomly assigned to consume an ultra-processed diet or an unprocessed diet for a period of 2 weeks. Following a 2 -week wash out period, participants were assigned to the alternate diet for an additional 2 weeks. The meals provided to participants were matched for energy, macronutrients, fiber, sodium, and sugar content and participants were instructed to eat ad libitum. While following the ultra-processed diet, participants consumed more calories $(p<0.0001)$, carbohydrates $(p<0.0001)$, and fat $(p=$ $0.0004)$ and experienced significant weight gain $(0.9 \pm 0.3 \mathrm{~kg}, p=$ $0.009)$. While on the unprocessed diet, participants experienced significant weight loss $(0.9 \pm 0.3 \mathrm{~kg}, p=0.007)$.

\section{Hypertension and Cardiovascular Disease}

In a prospective study of 14,790 Spanish adults with a mean follow-up period of 9.1 years, participants with the highest intake of UPF had the greatest risk of developing hypertension (HR: 1.21, 95\% CI: 1.06-1.37) (8). The findings of this study, the SUN project, are especially robust considering that data collection commenced in 1999, bringing the total person-years for this cohort to 134,784 . In a similar vein, results from the NutriNetSanté French cohort also indicate that higher consumption of UPF is associated with increased risk for coronary heart disease (HR for absolute 10\% increase: 1.13, 95\% CI: 1.02-1.24), cardiovascular disease (HR for absolute 10\% increase: 1.12, 95\% CI: 1.05-1.20), and cerebrovascular diseases (HR for absolute $10 \%$ increase: $1.11,95 \% \mathrm{CI}: 1.01-1.21)$, even with adjustment for diet quality (9).

\section{Type-2 Diabetes Mellitus}

Srour and colleagues of the NutriNet-Santé French prospective cohort also assessed the association between UPF intake and type-2 diabetes (T2D) incidence (10). Consumption of UPF was shown to positively correlate with incident type-2 diabetes, and this association persisted after adjustment for metabolic comorbidities and diet quality.

\section{Cancer}

Consumption of UPF has also been tied to increased cancer incidence. Overall cancer risk and breast cancer risk were both found to increase in proportion to the amount of UPF in subjects' diets within the NutriNet-Santé French cohort (HR per 10\% increase: 1.12 , 95\% CI: $1.06-1.18$ and HR per 10\% increase: 1.11 , 95\% CI: 1.02-1.22, respectively) (11). 
TABLE 2 | Studies assessing the association between UPF intake and excess adiposity.

\begin{tabular}{|c|c|c|c|c|c|}
\hline Authors & Year & Study Design & Population & $\begin{array}{l}\text { Median follow } \\
\text { up period } \\
\text { (years) }\end{array}$ & Main Findings \\
\hline Beslay et al. (5) & 2020 & Prospective & $\begin{array}{l}\text { NutriNet-Santé cohort: } 110,260 \text { French } \\
\text { adults (age } 43.1 \pm 14.6 \text { years, } 78.2 \% \text { ㅇ) }\end{array}$ & 10 & $\begin{array}{l}\text { UPF intake is associated with } \\
\text { risk of overweight }\left(\mathrm{HR}_{10 \%}: \text { : }\right. \\
1.11,95 \% \mathrm{Cl}: 1.08-1.14) \text { and } \\
\text { obesity }\left(\mathrm{HR}_{10 \%}: 1.09,95 \%\right. \\
\mathrm{Cl} 1.05-1.13)\end{array}$ \\
\hline $\begin{array}{l}\text { Sandoval-Insausti } \\
\text { et al. (7) }\end{array}$ & 2020 & Prospective & $\begin{array}{l}\text { Seniors Study on Nutrition and } \\
\text { Cardiovascular Risk in Spain Seniors } \\
\text { (ENRICA-1) cohort: } 652 \text { Spanish elderly } \\
\text { adults (age } 67.1 \pm 5.8 \text { years, } 44 \% \text { ㅇ) }\end{array}$ & 6 & $\begin{array}{l}\text { UPF intake is associated with } \\
\text { greater odds of developing } \\
\text { abdominal obesity (OR: } 1.62 \text {, } \\
95 \% \mathrm{Cl}: 1.04-2.54)\end{array}$ \\
\hline Canhada et al. (43) & 2020 & Prospective & $\begin{array}{l}\text { Brazilian Longitudinal Study of Adult } \\
\text { Health (ELSA-Brasil) cohort: 11,827 } \\
\text { Brazilian adults (age 51.3 } \pm 8.7 \text { years, } \\
55.0 \% \text { o) }\end{array}$ & 3.8 & $\begin{array}{l}\text { UPF intake is associated with } \\
\text { being at an unhealthy weight } \\
\text { (RR: } 1.27,95 \% \mathrm{Cl}: 1.07-1.50) \text { as } \\
\text { well as weight gain (RR:1.33, } \\
\text { 95\% Cl: } 1.12-1.58)\end{array}$ \\
\hline Nardocci et al. (44) & 2020 & Cross-sectional & $\begin{array}{l}\text { Canadian Community Health Survey, cycle } \\
2.2 \text { respondents: } 19,363 \text { Canadian adults } \\
\text { (age } 45.99 \pm 18.1 \text { years, } 49.1 \% \text { o) }\end{array}$ & $\mathrm{n} / \mathrm{a}$ & $\begin{array}{l}\text { UPF intake is associated with } \\
\text { greater odds of being obese } \\
\text { (predicted OR: } 1.32 ; 95 \% \mathrm{Cl} \text { : } \\
1.05-1.57 \text { ) }\end{array}$ \\
\hline Hall et al. (21) & 2019 & $\mathrm{RCT}$ & $\begin{array}{l}20 \text { adults (age } 31.2 \pm 1.6 \text { years, } 50 \% \text { o) } \\
\text { randomly assigned to consume an } \\
\text { ultra-processed diet or an unprocessed } \\
\text { diet for a period of two weeks }\end{array}$ & $\mathrm{n} / \mathrm{a}$ & $\begin{array}{l}\text { Following an ultra-processed diet } \\
\text { led to greater intake of calories } \\
(p<0.0001) \text {, carbohydrates } \\
(p<0.0001) \text {, and fat }(p= \\
0.0004) \text {, as well as weight gain } \\
(0.9 \pm 0.3 \mathrm{~kg}, p=0.009)\end{array}$ \\
\hline Juul et al. (45) & 2018 & Cross-sectional & $\begin{array}{l}\text { National Health and Nutrition Examination } \\
\text { Survey (NHANES) respondents: a } \\
\text { nationally representative sample of 15,977 } \\
\text { American adults (age } 41.9 \pm 0.2 \text { years, } \\
50.6 \% \text { o) }\end{array}$ & $\mathrm{n} / \mathrm{a}$ & $\begin{array}{l}\text { UPF intake is associated with } \\
\text { significantly higher BMl and WC } \\
\text { and increased odds of } \\
\text { overweight (OR: } 1.48,95 \% \mathrm{Cl} \text { : } \\
1.25-1.76) \text {, obesity (OR: } 1.53 \text {, } \\
95 \% \mathrm{Cl} \text { : } 1.29-1.81 \text { ), and } \\
\text { abdominal obesity (OR: } 1.62 \text {, } \\
95 \% \mathrm{Cl} \text { : } 1.39-1.89 \text { ) }\end{array}$ \\
\hline $\begin{array}{l}\text { Mendonça et al. } \\
\text { (6) }\end{array}$ & 2016 & Prospective & $\begin{array}{l}\text { Seguimiento Universidad de Navarra } \\
\text { (SUN) Project cohort: } 8,451 \text { Spanish } \\
\text { adults (age } 37.6 \pm 11.0 \text { years, } 64.9 \% \text { @) }\end{array}$ & 8.9 & $\begin{array}{l}\text { UPF intake is associated with } \\
\text { increased risk of } \\
\text { overweight/obesity (adjusted HR: } \\
1.26 \text {; } 95 \% \mathrm{Cl}: 1.10-1.45 \text { ) }\end{array}$ \\
\hline Louzada et al. (46) & 2015 & Cross-sectional & $\begin{array}{l}\text { Brazilian Dietary Survey respondents: a } \\
\text { nationally representative sample of 30,243 } \\
\text { Brazilians; age in years, range (\%): } 10-19 \\
(24.2 \%), 20-39(41.3 \%), 40-59(26.0 \%) \text {, } \\
\text { and } \geq 60 \text { (8.5\%); } 50.2 \% \text { q }\end{array}$ & $\mathrm{n} / \mathrm{a}$ & $\begin{array}{l}\text { UPF intake is associated with } \\
\text { greater odds of being obese } \\
\text { (OR: } 1.98,95 \% \mathrm{Cl}: 1.26-3.12 \text { ) }\end{array}$ \\
\hline
\end{tabular}

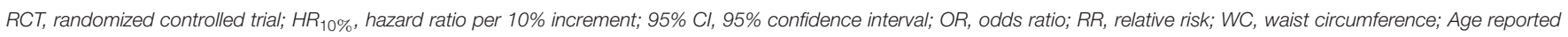
as Mean $\pm S D$ unless indicated otherwise; o, female.

\section{Mortality}

UPF also appear to adversely impact mortality risk. Using data from a sub-set $(n=44,551$, mean age $56.7 \pm 7.5$ years, $73.1 \%$ female) of the NutriNet-Santé French cohort, researchers discovered that after adjusting for common socioeconomic and lifestyle confounders, higher intake of UPF was associated with an elevated risk of death from all causes (HR per 10\% increase: 1.14, 95\% CI: 1.04-1.27) after a median follow up time of 7.1 years (12). In the SUN Spanish cohort study, participants who reported the highest consumption of UPF had the highest risk of allcause mortality (HR: 1.62, 95\% CI: 1.13-2.33). This relationship was also dose-dependent ( $p$ for trend: 0.005) (13). The same association has been found among US adults (14).

\section{POTENTIAL MECHANISMS WHICH MAY EXPLAIN THE LINK BETWEEN THE INTAKE OF ULTRA-PROCESSED FOODS AND CHRONIC DISEASES}

\section{Decreased Nutritional Quality: Energy Density, Sodium, Sugar, and Fiber}

The high energy density of UPF may partially explain the association between UPF intake and excess adiposity. This is because the energy density of foods in one's diet is predictive of overall energy intake (47). Studies show that as people incorporate more energy dense foods into their diets, they 
typically do a poor job of adjusting their overall energy intake. This leads to what has been termed as "passive overconsumption (47)."

As intake of UPF foods increases, intake of saturated fat, free sugars, and sodium all rise while fiber, protein, and potassium intake fall (48). UPF also tend to be high in sodium relative to minimally processed foods. Independent of other dietary factors, high sodium intake has been identified as a contributor to death due to cardio-metabolic dysfunction $(49,50)$. The same holds true for SSBs, which are ultra-processed (49). SSB consumption may also increase one's risk of developing hypertension (51) and CVD (52). Furthermore, the consumption of added sugars is significantly associated with CVD mortality risk (37). It has been estimated that $89.7 \%$ of energy provided by added sugars in a typical American diet comes from UPF (53).

The low fiber content of UPF may also play a role in the link between UPF intake and cardio-metabolic disease. Based on data compiled in an umbrella review of 18 meta-analyses, Veronese and colleagues found that high fiber intake was protective against cardiovascular disease incidence and mortality, coronary artery disease, and cancers associated with the gastrointestinal system (54). Ultra-processing typically removes the protective fiber layer of grains.

\section{Contaminants and Neoformed Compounds}

Acrylamide, acrolein, polycyclic aromatic hydrocarbons (PAH), and furan are some common compounds associated with the preparation of UPF. Acrylamide is an organic compound that is formed when starchy foods are cooked at high temperatures. Potato chips and breakfast cereals are two examples of foods that may contain high amounts of acrylamide (55). Acrylamide may have adverse effects on hormone regulation, signal propagation across nerve fibers, reproductive health, and cancer formation, however this evidence comes primarily from animal studies (55). Dietary exposure to acrylamide as assessed by hemoglobin biomarkers was shown to be significantly associated with death from all causes in the NHANES 2003-2006 cohort ( $p$ for trend $=0.0124$ ) (56).

Acrolein is an unsaturated aldehyde that is produced as a result of cooking fats at high temperatures. In the Louisville Healthy Heart Study, acrolein exposure measured via a urinary biomarker was associated with increased CVD risk (57). PAH are produced during dry, high-heat cooking. When solid fuels such as wood or coal are used to prepare food, PAH from the burning of those fuels can contaminate the food. According to data from the NHANES 2005-2014 cohort, PAH exposure positively correlates with diabetes prevalence (58). Similarly, Ranjbar and colleagues determined that dyslipidemia, hypertension, excess adiposity, and type-2 diabetes may all be related to $\mathrm{PAH}$ exposure (59). Furan is an organic compound that is also produced during high heat cooking as a consequence of thermal degradation. The European Food Safety Authority has stated publicly that while there are a plethora of uncertainties in the risk assessment of furan, this compound has been shown to induce oxidative stress in animal models and has the potential to be hepatotoxic (60).

\section{Alteration of the Food Matrix}

Processing foods alters the food matrix and often involves the removal of protective food structures. For instance, refined grains and their products are very low in fiber due to the removal of the bran layer. In animal studies, fiber intake has been shown to be protective against obesity in the context of a high fat diet (61). Likewise, dietary polyphenols, which are also greatly reduced during ultra-processing, have been demonstrated to fortify the gut microbiome against inflammation associated with a high fat $\operatorname{diet}(62)$.

Ultra-processing also breaks down cellular structures and frees nutrients in food from the compartments in which they are normally contained, producing acellular nutrients (63). Destruction of the cell wall facilitates rapid digestion and may also spur bacterial overgrowth in the small intestine and alter gut microbiome composition (64). A high proliferation of gut bacteria can precipitate low grade inflammation in the host, which can affect not only local tissues but also the entire organism, as bacteria associated with inflammation and metabolic disease can translocate and enter the systemic circulation $(65,66)$. The composition of the gut microbiome is largely reflective of the host diet, and high intake of simple sugars favors the growth of microorganisms that can metabolize this substrate. As a consequence, microbial diversity may shift to favor leptin resistance, hyperphagia, and the development of chronic diseases $(64,67)$.

\section{CONCLUSIONS}

The rising popularity of ultra-processed foods in Latin America is significantly associated with the prevalence of non-communicable diseases in this region of the world. This association is graded and reflects increasing urbanicity and interplay with foreign markets in the Latin American economy. While countries like Mexico and Chile appear to be consuming the most UPF per capita, these findings represent a major public health concern for all of Latin America. It would be prudent of policy makers to design measures that facilitate production, promotion, and access to healthy foods in order to reverse this trend. Promoting good health practices enhances quality of life not only at the individual level, but ultimately at the global level.

\section{AUTHOR CONTRIBUTIONS}

RM, MA, and JS all contributed to this manuscript through conceptualization, acquisition and interpretation of relevant data, and preparation of the final approved paper. RM and MA contributed equally to the writing of this manuscript. All authors contributed to the article and approved the submitted version.

\section{ACKNOWLEDGMENTS}

This work was supported by Universidad Peruana Unión and Loma Linda University. 


\section{REFERENCES}

1. Monteiro CA, Cannon G, Lawrence M, Costa Louzada ML, Pereira Machado P. Ultra-Processed Foods, Diet Quality, and Health Using the NOVA Classification System. Rome: FAO (2019). p. 48

2. Pan American Health Organization. Ultra-processed Food and Drink Products in Latin America: Trends, Impact on Obesity, Policy Implications. Washington, DC: Pan American Health Organization (2015). p. 76.

3. Otto MCDO, Afshin A, Micha R, Khatibzadeh S, Fahimi S, Singh G, et al. The impact of dietary and metabolic risk factors on cardiovascular diseases and type 2 diabetes mortality in Brazil. PLoS ONE. (2016) 11:e0151503-e. doi: 10.1371/journal.pone.0151503

4. Popkin BM, Reardon T. Obesity and the food system transformation in Latin America. Obes Rev. (2018) 19:1028-64. doi: 10.1111/obr.12694

5. Beslay M, Srour B, Méjean C, Allès B, Fiolet T, Debras C, et al. Ultra-processed food intake in association with BMI change and risk of overweight and obesity: A prospective analysis of the French NutriNet-Santé cohort. PLoS Med. (2020) 17:e1003256. doi: 10.1371/journal.pmed.1003256

6. Mendonça RD, Pimenta AM, Gea A, de la Fuente-Arrillaga C, MartinezGonzalez MA, Lopes AC, et al. Ultraprocessed food consumption and risk of overweight and obesity: the University of Navarra Follow-Up (SUN) cohort study. Am J Clin Nutr. (2016) 104:1433-40. doi: 10.3945/ajcn.116.135004

7. Sandoval-Insausti H, Jiménez-Onsurbe M, Donat-Vargas C, Rey-García J, Banegas JR, Rodríguez-Artalejo F, et al. Ultra-processed food consumption is associated with abdominal obesity: A prospective cohort study in older adults. Nutrients. (2020) 12:2368. doi: 10.3390/nu12082368

8. Mendonça RD, Lopes AC, Pimenta AM, Gea A, Martinez-Gonzalez MA, Bes-Rastrollo M. Ultra-processed food consumption and the incidence of hypertension in a Mediterranean cohort: The Seguimiento Universidad de Navarra Project. Am J Hypertens. (2017) 30:358-66. doi: 10.1093/ajh/hpw137

9. Srour B, Fezeu LK, Kesse-Guyot E, Allès B, Méjean C, Andrianasolo RM, et al. Ultra-processed food intake and risk of cardiovascular disease: prospective cohort study (NutriNet-Santé). BMJ. (2019) 365:11451. doi: 10.1136/bmj.11451

10. Srour B, Fezeu LK, Kesse-Guyot E, Allès B, Debras C, Druesne-Pecollo N, et al. Ultra-processed food consumption and risk of type 2 diabetes among participants of the NutriNet-Santé prospective cohort. JAMA Intern Med. (2020) 180:283-91. doi: 10.1001/jamainternmed.2019.5942

11. Fiolet T, Srour B, Sellem L, Kesse-Guyot E, Allès B, Méjean C, et al. Consumption of ultra-processed foods and cancer risk: Results from NutriNet-Santé prospective cohort. BMJ. (2018) 360:k322. doi: 10.1136/bmj.k322

12. Schnabel L, Kesse-Guyot E, Allès B, Touvier M, Srour B, Hercberg S, et al. Association between ultra-processed food consumption and risk of mortality among middle-aged adults in France. JAMA Intern Med. (2019) 179:490-8. doi: 10.1001/jamainternmed.2018.7289

13. Rico-Campà A, Martínez-González MA, Alvarez-Alvarez I, Mendonça RD, de la Fuente-Arrillaga C, Gómez-Donoso C, et al. Association between consumption of ultra-processed foods and all-cause mortality: SUN prospective cohort study. BMJ. (2019) 365:11949. doi: 10.1136/bmj. 11949

14. Kim H, Hu EA, Rebholz CM. Ultra-processed food intake and mortality in the USA: results from the Third National Health and Nutrition Examination Survey (NHANES III, 1988-1994). Public Health Nutr. (2019) 22:1777-85. doi: $10.1017 / \mathrm{s} 1368980018003890$

15. Poti JM, Mendez MA, Ng SW, Popkin BM. Is the degree of food processing and convenience linked with the nutritional quality of foods purchased by US households? Am J Clin Nutr. (2015) 101:1251-62. doi: 10.3945/ajen.114.100925

16. Suez J, Korem T, Zilberman-Schapira G, Segal E, Elinav E. Non-caloric artificial sweeteners and the microbiome: findings and challenges. Gut Microbes. (2015) 6:149-55. doi: 10.1080/19490976.2015.1017700

17. Chassaing B, Koren O, Goodrich JK, Poole AC, Srinivasan S, Ley RE, et al. Dietary emulsifiers impact the mouse gut microbiota promoting colitis and metabolic syndrome. Nature. (2015) 519:92-6. doi: 10.1038/nature14232

18. Martino JV, Van Limbergen J, Cahill LE. The role of carrageenan and carboxymethylcellulose in the development of intestinal inflammation. Front Pediatr. (2017) 5:96. doi: 10.3389/fped.2017.00096
19. Cimmino I, Fiory F, Perruolo G, Miele C, Beguinot F, Formisano P, et al. Potential mechanisms of bisphenol A (BPA) contributing to human disease. Int J Mol Sci. (2020) 21:5761. doi: 10.3390/ijms21165761

20. Buckley JP, Kim H, Wong E, Rebholz CM. Ultra-processed food consumption and exposure to phthalates and bisphenols in the US National Health and Nutrition Examination Survey, 2013-2014. Environ Int. (2019) 131:105057. doi: 10.1016/j.envint.2019.105057

21. Hall KD, Ayuketah A, Brychta R, Cai H, Cassimatis T, Chen KY, et al. Ultraprocessed diets cause excess calorie intake and weight gain: An inpatient randomized controlled trial of ad libitum food intake. Cell Metab. (2019) 30:226. doi: 10.1016/j.cmet.2019.05.020

22. Lawrence MA, Baker PI. Ultra-processed food and adverse health outcomes. BMJ. (2019) 365:12289. doi: 10.1136/bmj.12289

23. Monteiro CA, Cannon G, Levy RB, Moubarac JC, Louzada MLC, Rauber F, et al. Ultra-processed foods: What they are and how to identify them. Public Health Nutr. (2019) 22:936-41. doi: 10.1017/S1368980018003762

24. Costa Louzada ML, Martins AP, Canella DS, Baraldi LG, Levy RB, Claro RM, et al. Ultra-processed foods and the nutritional dietary profile in Brazil. Rev Saude Publica. (2015) 49:38. doi: 10.1590/s0034-8910.2015049006132

25. Gibney MJ, Forde CG, Mullally D, Gibney ER. Ultra-processed foods in human health: a critical appraisal. Am J Clin Nutr. (2017) 106:717-24. doi: $10.3945 /$ ajcn.117.160440

26. Oteng A-B, Kersten S. Mechanisms of action of trans fatty acids. Adv Nutr. (2020) 11:697-708. doi: 10.1093/advances/nmz125

27. Gayrard V, Lacroix MZ, Grandin FC, Collet SH, Mila H, Viguié C, et al. Oral systemic bioavailability of bisphenol A and bisphenol S in pigs. Environ Health Perspect. (2019) 127:77005. doi: 10.1289/ehp4599

28. Carmody RN, Wrangham RW. Cooking and the human commitment to a high-quality diet. Cold Spring Harb Symp Quant Biol. (2009) 74:427-34. doi: 10.1101/sqb.2009.74.019

29. Tomas M, Beekwilder J, Hall RD, Sagdic O, Boyacioglu D, Capanoglu E. Industrial processing versus home processing of tomato sauce: Effects on phenolics, flavonoids and in vitro bioaccessibility of antioxidants. Food Chem (2017) 220:51-8. doi: 10.1016/j.foodchem.2016.09.201

30. Martorell R, de Romaña DL. Components of successful staple food fortification programs: Lessons from Latin America. Food Nutr Bull. (2017) 38:384-404. doi: 10.1177/0379572117707890

31. van Gool JD, Hirche H, Lax H, De Schaepdrijver L. Folic acid and primary prevention of neural tube defects: a review. Reprod Toxicol. (2018) 80:73-84. doi: 10.1016/j.reprotox.2018.05.004

32. Wirth R, Dziewas R, Beck AM, Clavé P, Hamdy S, Heppner HJ, et al. Oropharyngeal dysphagia in older persons - from pathophysiology to adequate intervention: A review and summary of an international expert meeting. Clin Interv Aging. (2016) 11:189-208. doi: 10.2147/cia.S97481

33. Martins APB, Levy RB, Claro RM, Moubarac JC, Monteiro CA. Increased contribution of ultra-processed food products in the Brazilian diet (1987-2009). Revista de Saude Publica. (2013) 47:656-65. doi: 10.1590/S0034-8910.2013047004968

34. International Diabetes Federation, Diabetes Atlas. Diabetes Prevalence (\% of population ages 20 to 79). Dataset: World Development Indicators (2021).

35. Cornwell B, Villamor E, Mora-Plazas M, Marin C, Monteiro CA, Baylin A. Processed and ultra-processed foods are associated with lower-quality nutrient profiles in children from Colombia. Public Health Nutr. (2018) 21:142-7. doi: 10.1017/S1368980017000891

36. Cediel G, Reyes M, da Costa Louzada ML, Martinez Steele E, Monteiro CA, Corvalán C, et al. Ultra-processed foods and added sugars in the Chilean diet (2010). Public Health Nutr. (2018) 21:125-33. doi: $10.1017 /$ S1368980017001161

37. Yang Q, Zhang Z, Gregg EW, Flanders WD, Merritt R, Hu FB. Added sugar intake and cardiovascular diseases mortality among US adults. JAMA Intern Med. (2014) 174:516-24. doi: 10.1001/jamainternmed.2013.13563

38. Kovalskys I, Rigotti A, Koletzko B, Fisberg M, Gómez G, HerreraCuenca $\mathrm{M}$, et al. Latin American consumption of major food groups: Results from the ELANS study. PLoS ONE. (2019) 14:e0225101-e. doi: 10.1371/journal.pone.0225101

39. Goodman D, González-Rivas JP, Jaacks LM, Duran M, Marulanda MI, Ugel E, et al. Dietary intake and cardiometabolic risk factors among 
Venezuelan adults: a nationally representative analysis. BMC Nutr. (2020) 6:61. doi: 10.1186/s40795-020-00362-7

40. Pérez-Ferrer C, Auchincloss AH, de Menezes MC, Kroker-Lobos MF, Cardoso LO, Barrientos-Gutierrez T. The food environment in Latin America: a systematic review with a focus on environments relevant to obesity and related chronic diseases. Public Health Nutr. (2019) 22:3447-64. doi: $10.1017 / \mathrm{s} 1368980019002891$

41. Harris JL, Kalnova SS. Food and beverage TV advertising to young children: Measuring exposure and potential impact. Appetite. (2018) 123:49-55. doi: 10.1016/j.appet.2017.11.110

42. Chemas-Velez MM, Gómez LF, Velasquez A, Mora-Plazas M, Parra DC, Scoping review of studies on food marketing in Latin America: Summary of existing evidence and research gaps. Rev Saude Publica. (2020) 53:107. doi: 10.11606/s1518-8787.2019053001184

43. Canhada SL, Luft VC, Giatti L, Duncan BB, Chor D, Fonseca M, et al. Ultra-processed foods, incident overweight and obesity, and longitudinal changes in weight and waist circumference: the Brazilian Longitudinal Study of Adult Health (ELSA-Brasil). Public Health Nutr. (2020) 23:1076-86. doi: $10.1017 / \mathrm{s} 1368980019002854$

44. Nardocci M, Leclerc BS, Louzada ML, Monteiro CA, Batal M, Moubarac JC. Consumption of ultra-processed foods and obesity in Canada. Can J Public Health. (2019) 1101):4-14. doi: 10.17269/s41997-018-0130-x

45. Juul F, Martinez-Steele E, Parekh N, Monteiro CA, Chang VW. Ultraprocessed food consumption and excess weight among US adults. Br J Nutr. (2018) 120:90-100. doi: 10.1017/s0007114518001046

46. Louzada MLdC, Baraldi LG, Steele EM, Martins APB, Canella DS, Moubarac JC, et al. Consumption of ultra-processed foods and obesity in Brazilian adolescents and adults. Prev Med. (2015) 81:9-15. doi: 10.1016/j.ypmed.2015.07.018

47. Prentice AM, Jebb SA. Fast foods, energy density and obesity: a possible mechanistic link. Obes Rev. (2003) 4:187-94. doi: 10.1046/j.1467-789x.2003.00117.x

48. Rauber F, Louzada MLdC, Steele EM, Millett C, Monteiro CA, Levy RB. Ultra-processed food consumption and chronic non-communicable diseasesrelated dietary nutrient profile in the UK (2008-2014). Nutrients. (2018) 10. doi: 10.3390/nu10050587

49. Micha R, Peñalvo JL, Cudhea F, Imamura F, Rehm CD, Mozaffarian D. Association between dietary factors and mortality from heart disease, stroke, and type 2 diabetes in the United States. JAMA. (2017) 317:912-24. doi: 10.1001/jama.2017.0947

50. Mozaffarian D, Fahimi S, Singh GM, Micha R, Khatibzadeh S, Engell RE, et al. Global sodium consumption and death from cardiovascular causes. $N$ Engl J Med. (2014) 371:624-34. doi: 10.1056/NEJMoal304127

51. Jayalath VH, de Souza RJ, Ha V, Mirrahimi A, Blanco-Mejia S, Di Buono M, et al. Sugar-sweetened beverage consumption and incident hypertension: a systematic review and meta-analysis of prospective cohorts. Am J Clin Nutr. (2015) 102:914-21. doi: 10.3945/ajcn.115.107243

52. Xi B, Huang Y, Reilly KH, Li S, Zheng R, Barrio-Lopez MT, et al. Sugarsweetened beverages and risk of hypertension and CVD: a dose-response meta-analysis. Br J Nutr. (2015) 113:709-17. doi: 10.1017/s0007114514004383

53. Martínez Steele E, Baraldi LG, Louzada ML, Moubarac JC, Mozaffarian D, Monteiro CA. Ultra-processed foods and added sugars in the US diet: evidence from a nationally representative cross-sectional study. BMJ Open. (2016) 6:e009892. doi: 10.1136/bmjopen-2015-009892

54. Veronese N, Solmi M, Caruso MG, Giannelli G, Osella AR, Evangelou E, et al. Dietary fiber and health outcomes: an umbrella review of systematic reviews and meta-analyses. Am J Clin Nutr. (2018) 107:436-44. doi: 10.1093/ajen/nqx082
55. Semla M, Goc Z, Martiniaková M, Omelka R, Formicki G. Acrylamide: a common food toxin related to physiological functions and health. Physiol Res. (2017) 66:205-17. doi: 10.33549/physiolres.933381

56. Huang M, Jiao J, Wang J, Chen X, Zhang Y. Associations of hemoglobin biomarker levels of acrylamide and all-cause and cardiovascular disease mortality among U.S. adults: National Health and Nutrition Examination Survey 2003-2006. Environ Pollut. (2018) 238:852-8. doi: 10.1016/j.envpol.2018.03.109

57. DeJarnett N, Conklin DJ, Riggs DW, Myers JA, O’Toole TE, Hamzeh I, et al. Acrolein exposure is associated with increased cardiovascular disease risk. $J$ Am Heart Assoc. (2014) 3. doi: 10.1161/jaha.114.000934

58. Stallings-Smith S, Mease A, Johnson TM, Arikawa AY. Exploring the association between polycyclic aromatic hydrocarbons and diabetes among adults in the United States. Environ Res. (2018) 166:588-94. doi: 10.1016/j.envres.2018.06.041

59. Ranjbar M, Rotondi MA, Ardern CI, Kuk JL. Urinary biomarkers of polycyclic aromatic hydrocarbons are associated with cardiometabolic health risk. PLoS ONE. (2015) 10:e0137536-e. doi: 10.1371/journal.pone.0137536

60. Knutsen HK, Alexander J, Barregård L, Bignami M, Brüschweiler B, Ceccatelli S, et al. Risks for public health related to the presence of furan and methylfurans in food. EFSA J. (2017) 15:e05005. doi: 10.2903/j.efsa.2017.5005

61. Chassaing B, Miles-Brown J, Pellizzon M, Ulman E, Ricci M, Zhang L, et al. Lack of soluble fiber drives diet-induced adiposity in mice. Am J Physiol Gastrointest Liver Physiol. (2015) 309:G528-41. doi: 10.1152/ajpgi.00172.2015

62. Roopchand DE, Carmody RN, Kuhn P, Moskal K, Rojas-Silva P, Turnbaugh PJ, et al. Dietary polyphenols promote growth of the gut bacterium Akkermansia muciniphila and attenuate high-fat diet-induced metabolic syndrome. Diabetes. (2015) 64:2847-58. doi: 10.2337/db14-1916

63. Spreadbury I. Comparison with ancestral diets suggests dense acellular carbohydrates promote an inflammatory microbiota, and may be the primary dietary cause of leptin resistance and obesity. Diabetes Metab Syndr Obes. (2012) 5:175-89. doi: 10.2147/dmso.S33473

64. Zinöcker MK, Lindseth IA. The Western diet-microbiome-host interaction and its role in metabolic disease. Nutrients. (2018) 10:365. doi: 10.3390/nu10030365

65. Sato J, Kanazawa A, Ikeda F, Yoshihara T, Goto H, Abe H, et al. Gut dysbiosis and detection of "live gut bacteria" in blood of Japanese patients with type 2 diabetes. Diabetes Care. (2014) 37:2343-50. doi: 10.2337/dc13-2817

66. Mitra S, Drautz-Moses DI, Alhede M, Maw MT, Liu Y, Purbojati RW, et al. In silico analyses of metagenomes from human atherosclerotic plaque samples. Microbiome. (2015) 3:38. doi: 10.1186/s40168-0150100-y

67. Turnbaugh PJ, Bäckhed F, Fulton L, Gordon JI. Diet-induced obesity is linked to marked but reversible alterations in the mouse distal gut microbiome. Cell Host Microbe. (2008) 3:213-23. doi: 10.1016/j.chom.2008. 02.015

Conflict of Interest: The authors declare that the research was conducted in the absence of any commercial or financial relationships that could be construed as a potential conflict of interest.

Copyright (C) 2021 Matos, Adams and Sabaté. This is an open-access article distributed under the terms of the Creative Commons Attribution License (CC BY). The use, distribution or reproduction in other forums is permitted, provided the original author(s) and the copyright owner(s) are credited and that the original publication in this journal is cited, in accordance with accepted academic practice. No use, distribution or reproduction is permitted which does not comply with these terms. 